\title{
The Effect of Different Vegetable Oils on Cedar Wood Surface Energy: Theoretical and Experimental Fungal Adhesion
}

\author{
Fadoua Bennouna $\mathbb{D D}^{1,2}$ Moulay Sadiki ${ }^{1}{ }^{3}$ Soumya Elabed $\mathbb{D},,^{1,4}$ \\ Saad Ibnsouda Koraichi $\mathbb{D}^{1,4}$ and Mohammed Lachkar $\mathbb{D}^{2}$ \\ ${ }^{1}$ Laboratory of Microbial Biotechnology and Bioactive Molecules, \\ University Sidi Mohammed Ben Abdellah, Faculty of Science and Technology, Po. Box 2202, Fez 30007, Morocco \\ ${ }^{2}$ Engineering Laboratory of Organometallic, Molecular Materials and Environment, \\ University Sidi Mohammed Ben Abdellah, Faculty of Science, Po. Box 1796, Fez 30000, Morocco \\ ${ }^{3}$ Laboratory of Molecular Engineering, Valorization and Environment, University Ibn Zohr, \\ Faculty Polydisciplinary of Taroudant, BP. 271, Taroudant 83000, Morocco \\ ${ }^{4}$ Regional University Centre of Interface, University Sidi Mohammed Ben Abdellah, Po. Box 2626, Fez 30000, Morocco
}

Correspondence should be addressed to Fadoua Bennouna; fadoua.bennouna@usmba.ac.ma

Received 25 March 2021; Revised 3 December 2021; Accepted 15 December 2021; Published 13 January 2022

Academic Editor: Yingchao Su

Copyright (c) 2022 Fadoua Bennouna et al. This is an open access article distributed under the Creative Commons Attribution License, which permits unrestricted use, distribution, and reproduction in any medium, provided the original work is properly cited.

\begin{abstract}
Despite having been used for ages to preserve wood against several effects (biological attack and moisture effects) that cause its degradation, the effect of vegetable oils on the cedar wood physicochemical properties is poorly known. Thus, in this study, the hydrophobicity, electron-acceptor $\left(\gamma^{+}\right)$, and electron-donor $\left(\gamma^{-}\right)$properties of cedar wood before and after treatment with vegetable oils have been determined using contact angle measurement. The cedar wood has kept its hydrophobic character after treatment with the different vegetable oils. It has become more hydrophobic quantitatively with values of surface energy ranged from -25.84 to $-43.45 \mathrm{~mJ} / \mathrm{m}^{2}$ and more electron donors compared to the untreated sample. Moreover, the adhesion of four fungal strains (Penicillium commune (PDLd"), Thielavia hyalocarpa, Penicillium commune (PDLd10), and Aspergillus niger) on untreated and treated cedar wood was examined theoretically and experimentally. For untreated wood, the experimental adhesion showed a positive relationship with the results obtained by the extended Derjaguin-Landau-Verwey-Overbeek (XDLVO) approach which found that all fungal strains could adhere strongly to the cedar wood material. In contrast, this relationship was not always positive after treatment. The Environmental Scanning Electron Microscopy (ESEM) has shown that P. commune (PDLd10) and A. niger were found unable to adhere to the wood surface after treatment with sunflower and rapeseed oils. In addition, the results showed that the four fungal strains' adhesion was decreased with olive and linseed oils treatment except that of P. commune (PDLd10) treated with linseed oil.
\end{abstract}

\section{Introduction}

Cedar wood is one of the oldest building materials in Morocco. Its use dates back to the Idrisids dynasty for building historical monuments of the Medina of $\mathrm{Fez}$ (mosques, schools, houses, etc.). In addition to its numerous qualities (strength, visual appearance, and the good thermal insulation properties), wood hygroscopicity is an important property considered as a negative characteristic. Indeed, wet conditions create a very favorable environment for the growth of various wood-degrading biological organisms (fungi, bacteria, and insects) [1]. These latter adhere to this material and form biofilms that cause a discoloration on building materials [2-4], reduction of wood durability due to structural and chemical changes [5], degradation of the historical monuments, and therefore, a loss of our cultural heritage. The most important step in the biofilm formation process is the microbial adhesion to the substrate surface. It involves mainly the Van der Waals, electrostatic, and acidbase interactions. These latter depend on the physicochemical characteristics of material and the microbial surface, especially hydrophobicity, surface tension, and 
electron-donor-electron-acceptor properties [6-8]. Therefore, it is very important to understand the physicochemical characteristics of microbial cell and solid surfaces in order to predict the microbial adhesion.

The prediction of microbial adhesion on the surface of different materials was studied using the extended DLVO (XDLVO) theory which introduces other non-DLVO forces as polar forces of Lewis (acid-base interactions) compared to the classical DLVO theory which considers only the van der Waals and electrostatic forces [9, 10]. In addition, it was claimed that the XDLVO approach may be the promising model to explain the experimental findings of microbial adhesion obtained by the environmental scanning electronic microscopy (ESEM) technique.

Previous works have explored the effect of the plasma polymerization technique [11], thermal treatment [12-14], and plant extracts [15] on the wood surface physicochemical characteristics. In addition, some studies have been conducted on the chemistry of vegetable oils within wood [16]. Vegetable oils are widely used as raw renewable resources in biopolymer synthesis, due to their low toxicity and ease of multiple functionalization [17]. Hence, their versatile compositions permit them to engage in various types of chemical reactions for generating new monomers, with epoxidation being one of the main and widely applied chemical transformations $[18,19]$. The use of epoxy functional vegetable oil and reactive UV-absorber as pretreatment for Scots pine and sapwood [20] and on the effect of linseed and tung oils on wood and water uptake has been reported [21]. However, there are no investigations on the effect of vegetable oils on the cedar wood physicochemical properties and their antiadhesive activity against fungi associated with its deterioration. Vegetable oils are very complex structures, widely applied in coatings, which undergo as many as 9 modifications reaction types (epoxidation, transesterification, glycerolysis, amidation, etc.). Thus, the purpose of this work is

(i) To study the effect of sunflower oil, rapeseed oil, linseed oil, olive oil, and argan oil on the cedar wood physicochemical properties. These vegetable oils are ecofriendly and low priced, enhance the color of wood, and offer it excellent protection.

(ii) To predict fungal spores adhesion on treated cedar wood using theoretical and experimental evaluation.

\section{Materials and Methods}

2.1. Vegetable Oils. Vegetable oils are considered as being a natural resource. In addition to the fact that they do not have toxic chemical effects on the environment, vegetable oils are nonvolatile and low priced [22]. The oils used in this study were sunflower oil, rapeseed oil, linseed oil, olive oil, and argan oil, all of which were commercially available. Table 1 provides an overview of the chemical composition of each vegetable oil.

\subsection{Fungal Strain Growth Conditions. Four fungi (Penicillium} commune (PDLd"), Penicillium commune (PDLd10),
Thielavia hyalocarpa, and Aspergillus niger) were used in this study. They were isolated from cedar wood decayed from an old house in the old Medina of Fez (Morocco) and identified in the laboratory of microbial biotechnology $[25,26]$. These strains were grown in a malt-extract-agar medium at $25^{\circ} \mathrm{C}$ for 10 days. The fungal spores were then collected using sterile solution of $\mathrm{KNO}_{3}(0.1 \mathrm{M})$. The spore suspensions were centrifuged at $7000 \mathrm{rpm}$ for $15 \mathrm{~min}$ at $4^{\circ} \mathrm{C}$. The pellets obtained were washed with sterile $\mathrm{KNO}_{3}$ and resuspended in the same solution to a final concentration of $10^{7}-10^{8}$ spores/ $\mathrm{mL}$.

2.3. Wood Preparation. The cedar wood samples (Cedrus atlantica) were provided from a woodworking shop in $\mathrm{Fez}$ city, Morocco, September 2015. The roughness of the wood samples $(30 \times 10 \times 4 \mathrm{~mm})$ was set in a range from 0.8 to $1 \mu \mathrm{m}$ using a rugosimeter. At the end, the samples were cleaned with distilled water, oven-dried, and then, autoclaved at $121^{\circ} \mathrm{C}$ for $20 \mathrm{~min}$.

2.4. Wood Treatment. $20 \mu \mathrm{L}$ of pure vegetable oil was deposited to the cedar wood surface at room temperature $\left(25 \pm 2^{\circ} \mathrm{C}\right)$ for $1 \mathrm{~h}$ so that the surface of wood is dried [15]. The samples were analyzed with contact angle measurements in order to evaluate the effect of each vegetable oil on the cedar wood physicochemical properties. Experiments were conducted in duplicate.

2.5. Contact Angle Measurements and Surface Tension Components of Fungal Strains and Wood Surfaces. The Lifshitz-nan der Waals, acid-base, and surface free energy of fungal strains and wood samples were calculated from contact angle measurements which were realized by the sessile drop method using a goniometer (GBX Instruments) [27]. Three measurements of contact angles were made on each samples using three liquids (of which two must be polar: water (W) and formamide $(\mathrm{F})$ and one nonpolar: diiodomethane (D)) with well-known surface energy components (Table 2) [29].

For A. niger strain, the contact angle measurements were performed as described by Busscher et al. [30]. For that, $10 \mathrm{~mL}$ of the spore suspension already prepared was filtered on a cellulose acetate membrane filter of $0.45 \mu \mathrm{m}$. After a good drying of the filters (air drying for $30 \mathrm{~min}$ at room temperature), contact angles were measured. The measurements of the contact angle were carried out in duplicate for two different fungal lawns. The contact angle measurements of T. hyalocarpa and P. commune (PDLd10 and PDLd") were determined by [31, 32] following the same methodology mentioned above.

Once the contact angles were measured, the Lifshitz-van der Waals and acid-base surface tension components were obtained by the three equations of the following form [8]:

$\gamma_{L}(\cos \theta+1)=2\left(\gamma_{S}^{L W} \gamma_{L}^{L W}\right)^{1 / 2}+2\left(\gamma_{S}^{+} \gamma_{L}^{-}\right)^{1 / 2}+2\left(\gamma_{S}^{+} \gamma_{L}^{-}\right)^{1 / 2}$ 
TABLE 1: Chemical composition of different vegetable oils.

\begin{tabular}{lcccc}
\hline & Saturated fatty acid $(\mathrm{g} / 100 \mathrm{~g})$ & Monounsaturated fatty acid $(\mathrm{g} / 100 \mathrm{~g})$ & Polyunsaturated fatty acid $(\mathrm{g} / 100 \mathrm{~g})$ & Reference \\
\hline Sunflower oil & 10.4 & 28.2 & 57.5 & $*$ \\
Rapeseed oil & 6.98 & 60.5 & 26.3 & 66 \\
Linseed oil & 9.4 & 20.2 & 6.88 & $*$ \\
Olive oil & 13.8 & 75.2 & 33.3 & $*$ \\
Argan oil & 17.6 & 44.8 & $*$ \\
\hline
\end{tabular}

${ }^{*}$ French food composition table Ciqual [23] ANSES, the French agency for food, environmental, and occupational health safety. ${ }^{* *}$ USDA Food Composition Databases [24], United States Department of Agriculture, Agricultural Research Service.

TABle 2: Surface tension properties of pure liquids used to measure contact angles [28].

\begin{tabular}{lccc}
\hline Liquid & $\gamma^{L W}\left(\mathrm{~mJ} / \mathrm{m}^{2}\right)$ & $\gamma^{+}\left(\mathrm{mJ} / \mathrm{m}^{2}\right)$ & $\gamma^{-}\left(\mathrm{mJ} / \mathrm{m}^{2}\right)$ \\
\hline Water $\left(\mathrm{H}_{2} \mathrm{O}\right)$ & 21.8 & 25.5 & 25.5 \\
Formamide $\left(\mathrm{CH}_{3} \mathrm{NO}\right)$ & 39 & 2.3 & 39.6 \\
Diiodomethane $\left(\mathrm{CH}_{2} \mathrm{I}_{2}\right)$ & 50.5 & 0 & 0 \\
\hline
\end{tabular}

where $\theta$ : the contact angle, $\gamma^{L W}$ : the van der Waals free energy component, $\gamma^{+}$: the electron-acceptor component, $\gamma^{-}$: the electron-donor component, and $S$ and $L$ stand for the solid surface and liquid phases, respectively.

The surface free energy is formulated as

$$
\gamma_{S}^{\text {Tot }}=\gamma_{S}^{L W}+\gamma_{S}^{A B}
$$

where $\gamma_{S}^{A B}=2\left(\gamma_{S}^{-} \gamma_{S}^{+}\right)^{1 / 2}$ is the Lewis acid-base component.

The fungal strains and wood samples' hydrophobicity was evaluated through contact angle measurements and by the approach in [29]. In this approach, the degree of hydrophobicity of a specific material can be defined as the free energy of interaction between two entities of this latter when immersed in water (w): $\Delta$ Giwi. So, we said that the material is hydrophilic whether the interaction between the two entities is lower than the interaction of each entity with water $(\Delta \mathrm{Giwi}>0)$; otherwise, the material is considered as hydrophobic $\Delta$ Giwi $<0$. $\Delta$ Giwi is calculated as reported in the following formula:

$$
\Delta \text { Giwi }=-2 \gamma_{i w}=-2\left[\left(\left(\gamma_{i}^{L W}\right)^{1 / 2}-\left(\gamma_{w}^{L W}\right)^{1 / 2}\right)^{2}+2\left(\left(\gamma_{i}^{+} \gamma_{i}^{-}\right)^{1 / 2}+\left(\gamma_{w}^{+} \gamma_{w}^{-}\right)^{1 / 2}-\left(\gamma_{i}^{+} \gamma_{w}^{-}\right)^{1 / 2}-\left(\gamma_{w}^{+} \gamma_{i}^{-}\right)^{1 / 2}\right)\right]
$$

2.6. Total Free Energy of Interaction: The Extended DLVO Theory. The classical DLVO theory considers only the forces of van der Waals and electrostatic. This theory was expanded in [10] to take into account polar interaction called as nonDLVO force. The total free energy is the sum of the interfacial energies of Lifshitz-van der Waals $\Delta G^{L W}$ and Lewis $\Delta G^{A B}$. In this work, the electrical interactions were ignored because of the higher ionic strength the suspending solution $\mathrm{KNO}_{3}$ used $(0.1 \mathrm{M})[33,34]$.

$$
\Delta G^{\text {Total }}=\Delta G^{L W}+\Delta G^{A B} .
$$

The interaction between two flat surfaces $i$ and $j$ (microbial cell and substratum), separated by a medium (water), is written as

$$
\begin{aligned}
\Delta G^{L W} & =-2\left(\sqrt{\gamma_{i}^{L W}}-\sqrt{\gamma_{w}^{L W}}\right)\left(\sqrt{\gamma_{j}^{L W}}-\sqrt{\gamma_{w}^{L W}}\right), \\
\Delta G^{A B} & =-2\left[\sqrt{\gamma_{w}^{+}}\left(\sqrt{\gamma_{i}^{-}}+\sqrt{\gamma_{j}^{-}}-\sqrt{\gamma_{w}^{-}}\right)+\sqrt{\gamma_{w}^{-}}\left(\sqrt{\gamma_{i}^{+}}+\sqrt{\gamma_{j}^{+}}-\sqrt{\gamma_{w}^{+}}\right)-\sqrt{\gamma_{i}^{+} \gamma_{j}^{-}}-\sqrt{\gamma_{i}^{-} \gamma_{j}^{+}}\right] .
\end{aligned}
$$

Fungal spore attachment is favored if $\Delta G^{\text {Total }}$ is negative and unfavored in the opposite case ( $\Delta G^{\text {Total }}$ is positive).

2.7. Adhesion Experiments. After treating the wood samples with vegetable oils tested, they were immersed in spore suspension at a concentration of $10^{7}$ spores $/ \mathrm{mL}$ for $10 \mathrm{~h}$ at $25^{\circ} \mathrm{C}$ [26]. At the end of the contract period, the samples were rinsed three times with sterile distilled water to remove spores that have not adhered to the wood surface.

2.8. Environmental Scanning Electron Microscopy Analysis. All wood samples were analyzed by Environmental Scanning Electron Microscopy (ESEM) Quanta 200 equipped with a tungsten filament. The ESEM images obtained present 
precious information about the antiadhesion effect of each vegetable oil tested as well as the adhesion of strains studied. The percentage of fungal spores adhered to the wood surface was determined by the MATLAB software program ${ }^{\circledR}$ [33].

\section{Results and Discussion}

3.1. Effect of Vegetable Oils on the Physicochemical Properties of Cedar Wood. Table 3 summarizes the contact angles values and the surface energies, together with their $\gamma^{L W}, \gamma^{A B}$, $\gamma^{-}, \gamma^{+}$, and $\gamma^{\text {Tot }}$ of untreated and treated cedar wood. In line with the work in [35] and the approach in [29, 36], the untreated cedar wood surface was hydrophobic qualitatively with values of $\theta_{W}=87.13 \pm 0.15^{\circ}$ and quantitatively with values of $\Delta \mathrm{Giwi}=-59.29 \mathrm{~mJ} / \mathrm{m}^{2}$. Also, the results showed that the degree of hydrophobicity has not changed much qualitatively and quantitatively even after treatment of the wood surface with sunflower, rapeseed, linseed, olive, and argan oils. Indeed, the cedar wood has kept its hydrophobic character after treatment with values of the water contact angles ranged from $\theta_{W}=64.95 \pm 0.24$ to $73.95 \pm 0.29^{\circ}$ and values of surface energy ranged from -25.84 to $-43.45 \mathrm{~mJ} /$ $\mathrm{m}^{2}$. These findings confirm those found by Jiang and Kamdem [37] who reported that the northern red oak wood has kept its hydrophobic character after treatment with a copper ethanolamine solution $\left(\theta_{W}>100^{\circ}\right)$. However, unlike our results, several studies have shown that the untreated cedar wood sample, which was hydrophobic, has become more hydrophilic after treatment with essential oil components $[38,39]$ and Thymus vulgaris extracts $[15,31]$.

The results showed also the increasing of electron-donor character after treatment with values ranging from 10.66 to $17.66 \mathrm{~mJ} / \mathrm{m}^{2}$ compared to the initial value of the untreated wood which is $4.47 \mathrm{~mJ} / \mathrm{m}^{2}$. The values of the electron-acceptor character are almost negligible. These statements are consistent with those found by Mohammed-Ziegler et al. [40], who noted that the electron-donor character of European oak wood treated with octadecyltrichlorosilane and chlorotrimethylsilane was higher $\left(\gamma^{-}=2.3 \mathrm{~mJ} / \mathrm{m}^{2}\right.$ and $\gamma^{-}=5.4 \mathrm{~mJ} / \mathrm{m}^{2}$, respectively) than that of the control $\left(\gamma^{-}=0.3 \mathrm{~mJ} / \mathrm{m}^{2}\right)$.

3.2. Physicochemical Properties of Fungal Cells. The physicochemical properties (hydrophobicity, the surface free energy, acid-base, the Lifshitz-van der Waals component, and electron-donor and electron-acceptor parameters) of the four fungal strains studied are represented in Table 4. Penicillium commune (PDLd"), Thielavia hyalocarpa, and Penicillium commune (PDLd10) are qualitatively and quantitatively hydrophilic. The water contact angle values ranged from 36.11 to $41.90^{\circ}$ and 8.28 to $37.12 \mathrm{~mJ} / \mathrm{m}^{2}$ for the surface free energy. Aspergillus niger is qualitatively hydrophilic and quantitatively hydrophobic $\left(\Delta \mathrm{Giwi}=-12.57 \mathrm{~mJ} / \mathrm{m}^{2}\right)$. Interestingly, it can also be seen from Table 4 that all strains have high values of electrondonor character $\left(\gamma^{-}\right)$and low values of electron-acceptor character $\left(\gamma^{+}\right)$. Several studies have shown that almost all microbial cells have electron-donor character, especially those presented in [41].
The microbial cell surface properties depend mainly on its chemical composition, especially the protein/carbohydrate ratio [42-44]. In fact, spores which have greater protein/carbohydrate ratio have a rough surface and are more hydrophobic, unlike those with lower protein/carbohydrate ratio [45].

\subsection{Theoretical Evaluation of the Adhesion of Four Fungal} Strains to the Cedar Wood Surface before and after Treatment. A good understanding of the microbial adhesion phenomenon cannot be carried out without taking into account the mechanisms involved in the interaction between the microbial cell and substrate. As previously mentioned, the aim of this theoretical evaluation was to provide information about the adhesion of $P$. commune (PDLd"), T. hyalocarpa, $P$. commune (PDLd10), and A. niger to the cedar wood surface before and after treatment with different vegetable oils and, thus, determine all the forces that govern this adhesion.

The results obtained in Table 5 show that all fungal strains could adhere to the untreated wood surface $\left(\Delta G^{\text {Tot }}<0\right)$. A. niger is the strain that adheres more to the wood surface with a value of $\Delta G^{\text {Tot }}=-20.06 \mathrm{~mJ} / \mathrm{m}^{2}$, and $P$. commune (PDLd10) is the least-adhering strain with a value of $\Delta G^{\text {Tot }}=-3.49 \mathrm{~mJ} / \mathrm{m}^{2}$. Moreover, the values of the $\Delta G^{A B}$ component of the four fungal strains were higher than those of the $\Delta G^{L W}$ component. Indeed, for $P$. commune (PDLd10) and Aspergillus niger, the theoretical adhesion should be governed only by short-range forces (the acid-base interactions) because $\Delta G^{A B}$ is negative and $\Delta G^{L W}$ is positive. In contrast, for P. commune (PDLd") and T. hyalocarpa, the theoretical adhesion should be governed more by shortrange forces than long-range forces (both have a negative value, but $\Delta G^{A B}>\Delta G^{L W}$ ).

In addition, we noted that, after treatment with sunflower, rapeseed, linseed, and olive oils, the adhesion was not favorable in most cases. In other cases, the adhesion was still favorable, but it was decreased. Indeed, the adhesion was not favorable after treatment with olive oil for both $P$. commune (PDLd") and $P$. commune (PDLd10) with values of $\Delta G^{\mathrm{Tot}}=1.61 \mathrm{~mJ} / \mathrm{m}^{2}$ and $\Delta G^{\mathrm{Tot}}=4.27 \mathrm{~mJ} / \mathrm{m}^{2}$, respectively, and it was decreased after treatment with sunflower oil for A. niger $\left(\Delta G^{\mathrm{Tot}}=-1.26 \mathrm{~mJ} / \mathrm{m}^{2}\right)$ and rapeseed oil for Thielavia hyalocarpa $\left(\Delta G^{\mathrm{Tot}}=-4.55 \mathrm{~mJ} / \mathrm{m}^{2}\right)$. Moreover, the results showed that, for all strains studied, after treatment with argan oil, the adhesion is much more favorable than before treatment and the theoretical adhesion is governed by $\Delta G^{A B}$. By contrast, the theoretical adhesion for the strains studied is governed by $\Delta G^{L W}$ after treatment with sunflower, rapeseed oil, linseed, and olive oils.

3.4. Experimental Adhesion of Fungal Strains to the Cedar Wood Surface before and after Treatment. As shown in Figures 1(a) and $1(\mathrm{~g})$ and $2(\mathrm{a})$ and $2(\mathrm{~g})$, P. commune (PDLd"), T. hyalocarpa, P. commune (PDLd10), and A. niger are able to adhere greatly to the cedar wood with a percentage of adhesion of $26.78 \%, 13.95 \%, 22.48 \%$, and $22.32 \%$, respectively. They were found dispersed as single, pairs, and 
TABle 3: Contact angles values, surface energies, and their components of cedar wood before and after treatment.

\begin{tabular}{|c|c|c|c|c|c|c|c|c|c|}
\hline & \multicolumn{3}{|c|}{ Contact angles $\left({ }^{\circ}\right)$} & \multicolumn{5}{|c|}{$\begin{array}{c}\text { Surface energy: components and } \\
\text { parameters }\left(\mathrm{m} J / \mathrm{m}^{2}\right)\end{array}$} & \multirow[t]{2}{*}{$\Delta G_{i w i}$} \\
\hline & $\theta_{W}\left({ }^{\circ}\right)$ & $\theta_{F}(\circ)$ & $\theta_{D}\left({ }^{\circ}\right)$ & $\gamma^{L W}$ & $\gamma^{+}$ & $\gamma^{-}$ & $\gamma^{A B}$ & $\gamma^{\mathrm{Tot}}$ & \\
\hline Untreated wood & $87.13 \pm 0.15$ & $66.61 \pm 0.14$ & $24.41 \pm 0.47$ & 46.44 & 0.67 & 4.47 & 3.36 & 49.8 & -59.20 \\
\hline Treated with sunflower oil & $64.95 \pm 0.24$ & $49.75 \pm 0.38$ & $14.35 \pm 0.23$ & 48.93 & 0.60 & 17.66 & 5.87 & 54.8 & -25.84 \\
\hline Treated with rapeseed oil & $73.95 \pm 0.29$ & $55.60 \pm 0.09$ & $18.25 \pm 0.18$ & 48.15 & 0.31 & 10.66 & 5.05 & 53.2 & -43.45 \\
\hline Treated with linseed oil & $66.35 \pm 0.14$ & $47.05 \pm 0.43$ & $13.45 \pm 0.16$ & 49.18 & 0.02 & 14.12 & 0.97 & 50.15 & -37.10 \\
\hline Treated with olive oil & $70.05 \pm 0.29$ & $53.20 \pm 0.19$ & $9.05 \pm 0.86$ & 49.99 & 0.26 & 13.58 & 4.01 & 54 & -36.47 \\
\hline Treated with argan oil & $68.25 \pm 0.53$ & $46.25 \pm 0.20$ & $14.40 \pm 0.46$ & 49.09 & 0.03 & 11.59 & 1.51 & 50.6 & -43.44 \\
\hline
\end{tabular}

TABLE 4: Contact angles values, surface energies, and their components for four fungal strains.

\begin{tabular}{|c|c|c|c|c|c|c|c|c|c|c|}
\hline \multirow[t]{2}{*}{ Strains } & \multicolumn{3}{|c|}{ Contact angles $\left({ }^{\circ}\right)$} & \multicolumn{5}{|c|}{$\begin{array}{l}\text { Surface energy: components and } \\
\text { parameters }\left(\mathrm{mJ} / \mathrm{m}^{2}\right)\end{array}$} & \multirow[t]{2}{*}{$\Delta G_{i w i}$} & \multirow[t]{2}{*}{ Reference } \\
\hline & $\theta_{W}\left({ }^{\circ}\right)$ & $\theta_{F}\left({ }^{\circ}\right)$ & $\theta_{D}\left({ }^{\circ}\right)$ & $\gamma^{L W}$ & $\gamma^{+}$ & $\gamma^{-}$ & $\gamma^{A B}$ & $\gamma^{\text {Tot }}$ & & \\
\hline P. commune (PDLd") & $36.11 \pm 0.65$ & $43.62 \pm 0.75$ & $51.31 \pm 0.18$ & 33.5 & 0.2 & 51.9 & 6.8 & 40.3 & 37.12 & {$[31,32]$} \\
\hline T. hyalocarpa & $41.90 \pm 0.63$ & $45.10 \pm 0.19$ & $55.00 \pm 0.55$ & 31.5 & 0.5 & 44.90 & 9.2 & 40.7 & 26.86 & [32] \\
\hline P. commune (PDLd10) & $39.33 \pm 1.13$ & $31.73 \pm 0.93$ & $77.66 \pm 0.42$ & 18.66 & 7.97 & 36.06 & 33.9 & 52.56 & 8.28 & {$[31,32]$} \\
\hline A. niger & $48.31 \pm 0.26$ & $26.15 \pm 0.21$ & $15.05 \pm 0.98$ & 48.97 & 0.45 & 24.53 & 5.93 & 54.9 & -12.57 & This work \\
\hline
\end{tabular}

TABLE 5: The total interaction free energy $\Delta G^{\text {Tot }}$, the polar forces of Lewis $\Delta G^{A B}$, and apolar Lifshitz-van der Waals $\Delta G^{L W}$ of the adhesion of fungal strains studied for untreated and treated wood (in $\mathrm{mJ} / \mathrm{m}^{2}$ ).

\begin{tabular}{lcccccccccccc}
\hline & \multicolumn{3}{c}{$\begin{array}{c}\text { Penicillium commune } \\
\text { (PDLd") }\end{array}$} & \multicolumn{3}{c}{ Thielavia hyalocarpa } & \multicolumn{3}{c}{$\begin{array}{c}\text { Penicillium commune } \\
\text { (PDLd10) }\end{array}$} & \multicolumn{2}{c}{ Aspergillus niger } \\
& $\Delta G^{L W}$ & $\Delta G^{A B}$ & $\Delta G^{\mathrm{Tot}}$ & $\Delta G^{L W}$ & $\Delta G^{A B}$ & $\Delta G^{\mathrm{Tot}}$ & $\Delta G^{L W}$ & $\Delta G^{A B}$ & $\Delta G^{\mathrm{Tot}}$ & $\Delta G^{L W}$ & $\Delta G^{A B}$ & $\Delta G^{\mathrm{Tot}}$ \\
\hline Untreated wood & -4.80 & -8.79 & -13.60 & -4.03 & -11.53 & -15.56 & 1.50 & -4.99 & -3.49 & 6.48 & -26.54 & -20.06 \\
Treated with sunflower oil & -5.21 & 11.03 & 5.82 & -4.37 & 7.07 & 2.70 & 1.62 & 4.58 & 6.20 & 7.02 & -8.28 & -1.26 \\
Treated with rapeseed oil & -5.08 & 3.43 & -1.65 & -4.27 & -0.28 & -4.55 & 1.59 & 0.85 & 2.44 & 6.85 & -16.54 & -9.69 \\
Treated with linseed oil & -5.25 & 9.37 & 4.12 & -4.40 & 5.05 & 0.65 & 1.64 & 3.67 & 5.31 & 7.07 & -12.39 & -5.32 \\
Treated with olive oil & -5.38 & 6.99 & 1.61 & -4.51 & 3.12 & -1.39 & 1.68 & 2.59 & 4.27 & 7.25 & -12.87 & -5.62 \\
Treated with argan oil & -5.23 & -41.8 & -47.03 & -4.39 & -43.41 & -47.80 & 1.63 & -57.56 & -55.93 & 7.05 & -56.02 & -48.97 \\
\hline
\end{tabular}

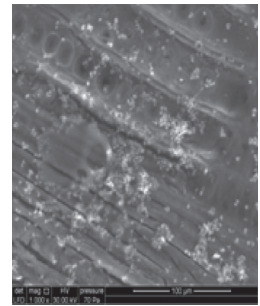

(a)

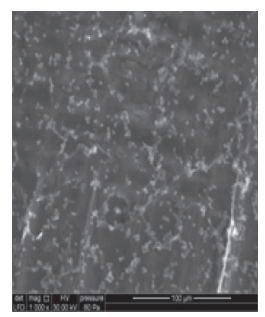

(g)

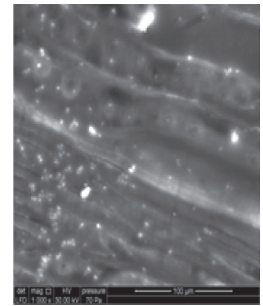

(b)

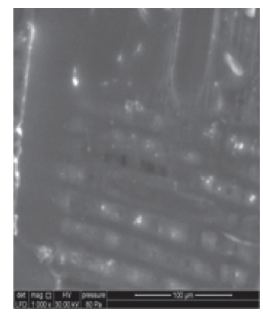

(h)

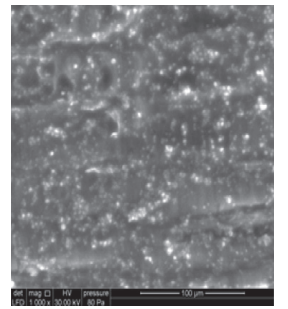

(c)

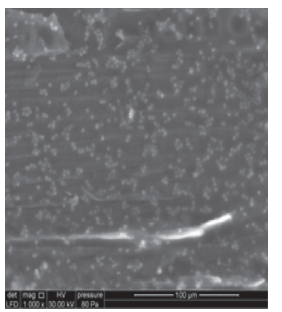

(i)

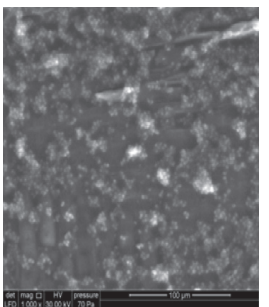

(d)

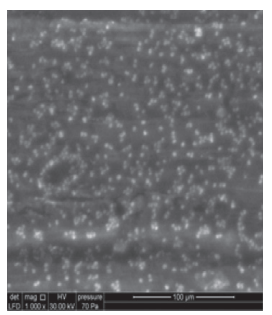

(j)

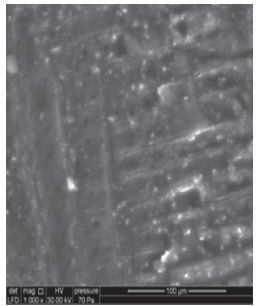

(e)

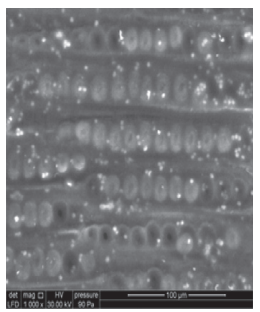

(k)

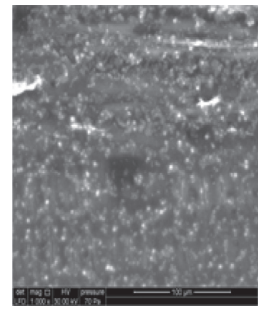

(f)

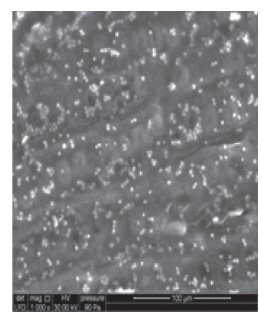

(1)

Figure 1: Electron micrographs of Penicillium commune (PDLd") (a-f) and Thielavia hyalocarpa (g-l) spores adhered on to untreated and treated wood, visualized by environmental scanning electron microscopy. (a, g) untreated wood, (b, h) olive oil treatment, (c, i) sunflower oil treatment, $(d, j)$ rapeseed oil treatment, $(e, k)$ linseed oil treatment, and $(f, l)$ argan oil treatment. 


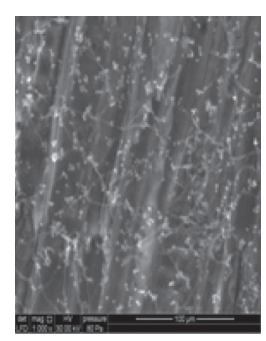

(a)

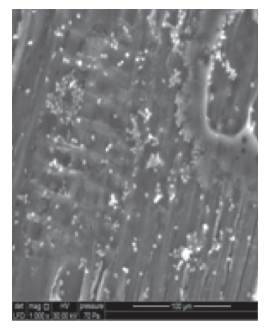

(g)

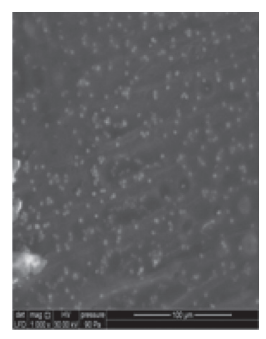

(b)

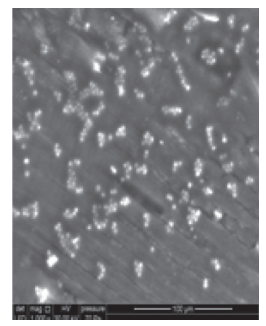

(h)

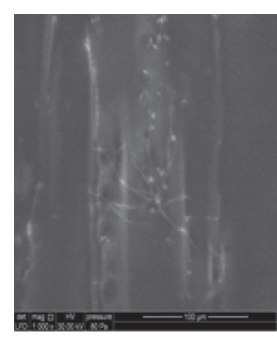

(c)

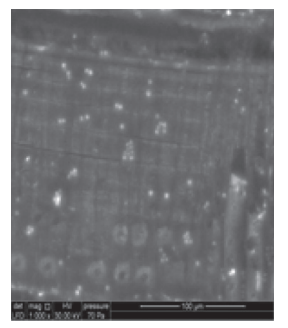

(i)

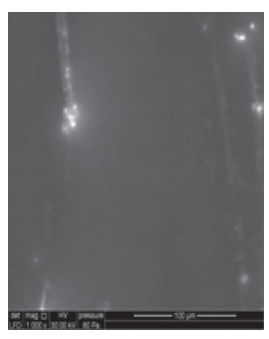

(d)

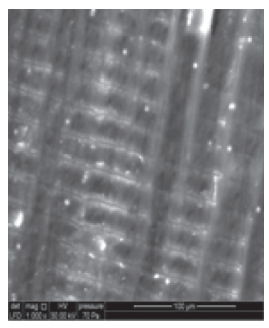

(j)

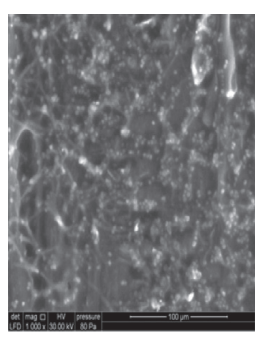

(e)

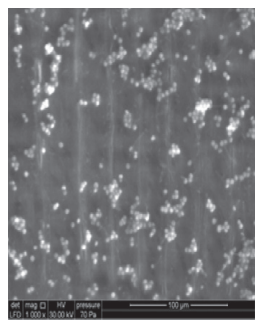

(k)

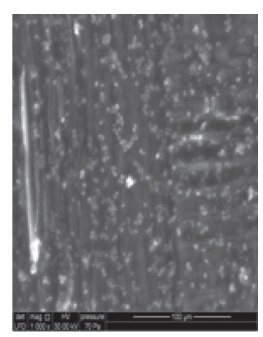

(f)

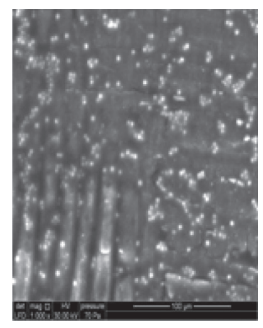

(l)

Figure 2: Electron micrographs of Penicillium commune (PDLd10) (a-f) and Aspergillus niger (g-l) spores adhered on to untreated and treated wood, visualized by environmental scanning electron microscopy. (a, g) untreated wood, (b, h) olive oil treatment, (c, i) sunflower oil treatment, $(d, j)$ rapeseed oil treatment, $(e, k)$ linseed oil treatment, and $(f, l)$ argan oil treatment.

into clusters of spores. These statements corroborate with those found by Sadiki et al. and El Abed et al. [31, 46] who studied the adhesion of fungal spores associated with the deterioration of cedar wood on the same wood species.

All fungal strains studied, which have a hydrophilic character, have adhered to the untreated cedar wood surface that has a hydrophobic character. These results are not corroborated with the correlation that said hydrophobic cells adhere more to hydrophobic surfaces and hydrophilic ones, as well as the results found in [7] showed that the hydrophobicity of several microorganisms is correlated with the adhesion to the hydrophobic solid surface. However, others authors reported that the acid-base interactions play a very important role in the microbial adhesion on a support beside the hydrophobicity character [47-49].

Interestingly, it can be seen from Figures $1(\mathrm{~b})$ and $1(\mathrm{~h})$ and 2(b) and 2(h) that the adhesion of all fungal strains was influenced by olive oil treatment, especially for P. commune (PDLd") and T. hyalocarpa with the percentage of adhesion of $12.54 \%$ and $10.31 \%$, respectively. Olive oil treatment has decreased the percentage of adherence from 22.48 to $10.91 \%$ for P. commune (PDLd10) and from 22.32 to $18.91 \%$ for A. niger. After treatment with sunflower oil, $P$. commune (PDLd10) and A. niger were found unable to adhere to the wood and presented low percentages of adhesion $(8.10 \%$ and $9.09 \%$, respectively) (Figures 2(c) and 2(i)). The same was detected after treatment with rapeseed oil with $6.05 \%$ and $11.31 \%$ of spores adhered (Figures $2(\mathrm{~d})$ and $2(\mathrm{j})$ ). However, the adhesion of $P$. commune (PDLd") and T. hyalocarpa has increased after treatment with sunflower $(28.49 \%$ for P. commune (PDLd") and $20.96 \%$ for T. hyalocarpa) and rapeseed oil (36.86\% for P. commune (PDLd") and 31.73\% for T. hyalocarpa). Linseed oil treatment has decreased the percentage of adherence for $P$. commune (PDLd"), T. hyalocarpa, and A. niger with percentages of adhesion of
$13.72 \%, 5.72 \%$, and $12.56 \%$, respectively, and increased from $22.48 \%$ to $36.65 \%$ for P. commune (PDLd10). The percentage of adhesion has increased using argan oil for all fungal strains (30.71\% for P. commune (PDLd"), $22.42 \%$ for T. hyalocarpa, $28.39 \%$ for P. Commune (PDLd10), and $24.76 \%$ for A. niger) and confirmed the theoretical prediction of adhesion. In summary, the antiadhesive effect of vegetable oils is fungal strain dependent as well as oil dependent.

These results can be attributed to secondary compounds resulting from the oxidation of fatty acids that can be found on the wood surface as well as the vegetable oil (fatty acids) reactions with wood. In fact, vegetable oils with higher degree of saturation are more sensitive to oxidation reaction. Polyunsaturated fatty acids have an important degree of oxidation unlike monounsaturated fatty acids. These latter have a different oxidation process: the monounsaturated fatty acid reacts with wood elements and becomes immobilized unlike the polyunsaturated ones which oxidize without binding to wood [16].

The relationships between the XDLVO approach and the adhesion experiments realized by ESEM were not always positive in our study. A contradiction between theoretical predictions and the results of the adhesion tests was noticed. Several factors can explain this difference. According to the work in [50], the XDLVO theory does not take into account biological-specific interactions and takes into account only the Lifshitz-van der Waals and acid-base components responsible of first steps of adhesion. Other authors reported that the cause of these significant discrepancies is due to the non-DLVO interactions and physical and chemical heterogeneities [51-53]. So, microbial adhesion is a multifactorial phenomenon in which other factors could contribute other than the Lifshitz-van der Waals and acid-base interactions. 


\section{Conclusions}

The treatment with different vegetable oils has increased the hydrophobicity quantitatively and the electron-donor component of the cedar wood surface. The antiadhesive effect of vegetable oils is fungal strain dependent as well as oil dependent. Among the tested oils, olive and linseed oils were seen to provide the best antiadhesive activity against $P$. commune (PDLd") and T. hyalocarpa. Sunflower and rapeseed oils have also worked well against the accession of $P$. commune (PDLd10) and $A$. niger. In fact, the $P$. commune (PDLd")/T. hyalocarpa adhesion after treatment with olive oil was governed by long-range forces (the van der Waals interactions) unlike the accession of $P$. commune (PDLd10)/ A. niger which was governed by short-range forces (the acidbase interactions) after treatment with sunflower and rapeseed oils.

\section{Data Availability}

No data were used to support this study.

\section{Conflicts of Interest}

The authors declare no conflicts of interest regarding the publication of this study.

\section{References}

[1] A. Lozhechnikova, K. Vahtikari, M. Hughes, and M. Österberg, "Toward energy efficiency through an optimized use of wood: the development of natural hydrophobic coatings that retain moisture-buffering ability," Energy and Buildings, vol. 105, pp. 37-42, 2015.

[2] R. J. Chedgy, P. I. Morris, Y. W. Lim, and C. Breuil, "Black stain of western red cedar (Thuja Plicata Donn) by Aureobasidium pullulans: the role of weathering," Wood Fiber Science, vol. 39, pp. 472-481, 2007.

[3] D. J. Dickinson, "Disfigurement of decorative timbers by blue stain fungi," International Pest Control, vol. 14, pp. 21-25, 1972.

[4] L. R. Gobakken and G. I. Vestøl, "Surface mould and blue stain fungi on coated Norway spruce cladding," International Biodeterioration \& Biodegradation, vol. 75, pp. 181-186, 2012.

[5] R. A. Blanchette, "A review of microbial deterioration found in archaeological wood from different environments," International Biodeterioration \& Biodegradation, vol. 46, no. 3, pp. 189-204, 2000.

[6] J. T. Gannon, V. B. Manilal, and M. Alexander, "Relationship between cell surface properties and transport of bacteria through soil," Applied and Environmental Microbiology, vol. 57, no. 1, pp. 190-193, 1991.

[7] M. C. Van Loosdrecht, J. Lyklema, W. Norde, G. Schraa, and A. J. Zehnder, "The role of bacterial cell wall hydrophobicity in adhesion," Applied and Environmental Microbiology, vol. 53, no. 8, pp. 1893-1897, 1987.

[8] C. J. Van Oss, "Acid-base interfacial interactions in aqueous media," Colloids and Surfaces A: Physicochemical and Engineering Aspects, vol. 78, pp. 1-49, 1993.

[9] R. Bos, H. C. Van der Mei, and H. J. Busscher, "Physico-chemistry of initial microbial adhesive interactions-its mechanisms and methods for study," FEMS Microbiology Reviews, vol. 23, no. 2, pp. 179-229, 1999.

[10] C. J. Van Oss, R. J. Good, and M. K. Chaudhury, "The role of van der waals forces and hydrogen bonds in "hydrophobic interactions" between biopolymers and low energy surfaces," Journal of Colloid and Interface Science, vol. 111, no. 2, pp. 378-390, 1986.

[11] H. A. Güleç, K. Sarıglu, and M. Mutlu, "Modification of food contacting surfaces by plasma polymerisation technique. Part I: determination of hydrophilicity, hydrophobicity and surface free energy by contact angle method," Journal of Food Engineering, vol. 75, no. 2, pp. 187-195, 2006.

[12] B. F. Bakar, S. Hiziroglu, and P. Md Tahir, "Properties of some thermally modified wood species," Materials \& Design, vol. 43, pp. 348-355, 2013.

[13] P. H. G. Cademartori, P. S. B. Dos Santos, L. Serrano, J. Labidi, and D. A. Gatto, "Effect of thermal treatment on physicochemical properties of gympie messmate wood," Industrial Crops and Products, vol. 45, pp. 360-366, 2013.

[14] C. A. S. Hill, Wood Modification: Chemical, Thermal and Other Processes, Wiley Serie in Renewable Resources, School of Agricultural and Forest Sciences, University of Wales, Bangor, UK, 2006.

[15] M. Sadiki, H. Barkai, S. Ibnsouda Koraichi, and S. Elabed, "The effect of the Thymus vulgaris extracts on the physicochemical characteristics of cedar wood using angle contact measurement," Journal of Adhesion Science and Technology, vol. 28, no. 19, pp. 1925-1934, 2014.

[16] G. Pagès, S. V. Dvinskikh, M. K. G. Johansson, and I. Furó, "Vegetable oil reactions within wood studied by direct 13C excitation with $1 \mathrm{H}$ decoupling and magic-angle sample spinning (MAS) NMR," Progress in Organic Coatings, vol. 75, no. 3, pp. 259-263, 2012.

[17] C. D. Varganici, L. Rosu, D. Rosu, F. Mustata, and T. Rusu, "Sustainable wood coatings made of epoxidized vegetable oils for ultraviolet protection," Environmental Chemistry Letters, vol. 19, no. 1, pp. 307-328, 2021.

[18] L. Rosu, C. D. Varganici, D. Rosu, I. Rosca, and T. Rusu, "Epoxy coatings based on modified vegetable oils for wood surface protection against fungal degradation," ACS Applied Materials \& Interfaces, vol. 12, no. 12, pp. 14443-14458, 2020.

[19] L. Rosu, C. D. Varganici, F. Mustata et al., "Enhancing the thermal and fungal resistance of wood treated with natural and synthetic derived epoxy resins," ACS Sustainable Chemistry Engineering, vol. 6, pp. 5470-5478, 2018.

[20] S. K. Olsson, H. Matsunaga, Y. Kataoka et al., "A SEM study on the use of epoxy functional vegetable oil and reactive UV-absorber as UV-protecting pretreatment for wood," Polymer Degradation Stability, vol. 113, pp. 40-45, 2015.

[21] M. Humar and B. Lesar, "Efficacy of linseed and tung oil treated wood against wood decay fungi and water uptake," International Biodeterioration Biodegradation, vol. 85, pp. 223-227, 2013.

[22] M. Alam, D. Akram, E. Sharmin, F. Zafar, and S. Ahmad, "Vegetable oil based eco-friendly coating materials: a review article," Arabian Journal of Chemistry, vol. 7, pp. 469-479, 2014.

[23] French Food Composition Table Ciqual, ANSES, the French Agency for Food, Environmental and Occupational Health Safety, https://pro.anses.fr/tableciqual/, 2013.

[24] USDA Food Composition Databases, United States Department of Agriculture, Agricultural Research Service, https://ndb. nal.usda.gov/ndb/, 2014. 
[25] M. Zyani, D. Mortabit, M. Mostakim et al., "Cellulolytic potential of fungi in wood degradation from an old house at the Medina of Fez," Annals of Microbiology, vol. 59, pp. 699-704, 2009.

[26] S. El Abed, F. Hamadi, H. Latrache, M. Iraqui Houssaini, and S. Ibnsouda Koraichi, "Adhesion of Aspergillus niger and Penicillium expansum spores on Fez cedar wood substrata," Annals of Microbiology, vol. 60, pp. 377-382, 2010.

[27] M. De Meijer, S. Haemers, W. Cobben, and H. Militz, "Surface energy determinations of wood: comparison of methods and wood species," Langmuir, vol. 16, pp. 9352-9359, 2000.

[28] C. J. Van Oss, "Long-range and short-range mechanisms of hydrophobic attraction and hydrophilic repulsion in specific and aspecific interactions," Journal of Molecular Recognition, vol. 16, pp. 177-190, 2003.

[29] C. J. Van Oss, M. K. Chaudhury, and R. J. Good, “Interfacial lifshitz-van der waals and polar interactions in macroscopic systems," Chemical Reviews, vol. 88, pp. 927-941, 1988.

[30] H. J. Busscher, A. H. Weerkamp, H. C. van der Mei, A. W. van Pelt, H. P. de Jong, and J. Arends, "Measurement of the surface free energy of bacterial cell surfaces and its relevance for adhesion," Applied and Environmental Microbiology, vol. 48, pp. 980-983, 1984.

[31] M. Sadiki, S. El abed, H. Barkai, F. Laachari, and S. Ibnsouda Koraichi, "The impact of Thymus vulgaris extractives on cedar wood surface energy: theoretical and experimental of Penicillium spores adhesion," Industrial Crops Products, vol. 77, pp. 1020-1027, 2015.

[32] M. Sadiki, S. El abed, H. Barkai, M. Balouiri, F. Z. El Bergadi, and S. Ibnsouda Koraichi, "Plant extracts effect on the cell fungal surface hydrophobicity and acid-base properties," Research Journal of Microbiology, vol. 11, pp. 139-145, 2016.

[33] F. Hamadi, H. Latrache, M. Mabrrouki et al., "Effect of $\mathrm{pH}$ on distribution and adhesion of Staphylococcus aureus to glass," Journal of Adhesion Science and Technology, vol. 19, pp. 73-85, 2005.

[34] S. El Abed, M. Mostakim, F. Berguadi et al., "Study of microbial adhesion on some wood species: theoretical prediction," Mikrobiologiia, vol. 80, pp. 43-49, 2011.

[35] E. A. Vogler, "Structure and reactivity of water at biomaterial surfaces," Advances Colloid Interface Science, vol. 74, pp. 69-117, 1998.

[36] C. J. Van Oss, L. Ju, M. K. Chaudhury, and R. J. Good, "Estimation of the polar parameters of the surface tension of liquids by contact angle measurements on gels," Journal of Colloid Interface Science, vol. 128, pp. 313-319, 1989.

[37] H. Jiang and D. P. Kamdem, "Characterization of the surface and the interphase of PVC-copper amine-treated wood composites," Applied Surface Science, vol. 256, pp. 4559-4563, 2010.

[38] H. Barkai, M. Sadiki, S. El abed, H. El harchli, S. Boutahari, and S. Ibnsouda Koraichi, "The effect of carvacrol and carvone treatments on the cedar wood surface physico-chemical properties," International Journal of Science Engineering Research, vol. 6, pp. 767-771, 2015.

[39] H. Barkai, S. El abed, M. Sadiki, M. Balouiri, H. Maataoui, and S. Ibnsouda Koraichi, "Evaluation of hydrophobic-hydrophilic properties and anti-adhesive potential of the treated cedar wood by two essential oil components against bioadhesion of Penicillium expansum spores," Journal of Applied Science, vol. 16, pp. 372-379, 2016.

[40] I. Mohammed-Ziegler, Á. Oszlánczi, B. Somfai et al., "Surface free energy of natural and surface-modified tropical and
European wood species," Journal of Adhesion Science Technology, vol. 18, pp. 687-713, 2004.

[41] H. C. Van Der Mei, R. Bos, and H. J. Busscher, "A reference guide to microbial cell surface hydrophobicity based on contact angles," Colloids Surfaces B Biointerfaces, vol. 11, pp. 213-221, 1998.

[42] R. Djeribi, Z. Boucherit, W. Bouchloukh et al., "A study of $\mathrm{pH}$ effects on the bacterial surface physicochemical properties of Acinetobacter baumannii," Colloids Surfaces B Biointerfaces, vol. 102, pp. 540-545, 2013.

[43] H. Latrache, A. El Ghmari, M. Karroua et al., "Relations between hydrophobicity tested by three methods and surface chemical composition of Escherichia coli," New Microbiology, vol. 25, pp. 75-82, 2002.

[44] C. Pelletier, C. Bouley, C. Cayuela, S. Bouttier, P. Bourlioux, and M. N. Bellon-Fontaine, "Cell surface characteristics of Lactobacillus casei subsp. casei, Lactobacillus paracasei subsp. paracasei, and Lactobacillus rhamnosus strains," Applied and Environmental Microbiology, vol. 63, pp. 1725-1731, 1997.

[45] L. B. Jeffs, I. J. Xavier, R. E. Matai, and G. G. Khachatourians, "Relationships between fungal spore morphologies and surface properties for entomopathogenic members of the general Beauveria, Metarhizium, Paecilomyces, Tolypocladium and Verticillium," Canadian Journal of Microbiology, vol. 45, pp. 936-948, 1999.

[46] S. El Abed, S. Ibnsouda Koraichi, A. Houari, and H. Latrache, "Experimental and theoretical investigations of the adhesion time of Penicillium spores to cedar wood surface," Materials Science Engineering C, vol. 33, pp. 1276-1281, 2013.

[47] S. McEldowney and M. Fletcher, "Variability of the influence of physicochemical factors affecting bacterial adhesion to polystyrene substrata," Applied Environmental Microbiology, vol. 52, pp. 460-465, 1986.

[48] I. H. Pratt-Terpstra, A. H. Weerkamp, and H. J. Busscher, "On a relation between interfacial free energy-dependent and noninterfacial free energy-dependent adherence of oral streptococci to solid substrata," Current Microbiology, vol. 16, pp. $311-313,1988$.

[49] J. Sjollema, H. C. Van Der Mei, H. M. W. Uyen, and H. J. Busscher, "The influence of collector and bacterial cell surface properties on the deposition of oral streptococci in a parallel plate flow cell," Journal of Adhesion Science Technology, vol. 4, pp. 765-777, 1990.

[50] S. Bayoudh, A. Othmane, F. Bettaieb, A. Bakhrouf, H. Ben Ouada, and L. Ponsonnet, "Quantification of the adhesion free energy between bacteria and hydrophobic and hydrophilic substrata," Materials Science Engineering C, vol. 26, pp. 300-305, 2006.

[51] Z. Adamczyk and P. Weroński, "Application of the DLVO theory for particle deposition problems," Advances Colloid Interface Science, vol. 83, pp. 137-226, 1999.

[52] J. Y. Chen, C. H. Ko, S. Bhattacharjee, and M. Elimelech, "Role of spatial distribution of porous medium surface charge heterogeneity in colloid transport," Colloids Surfaces A Physicochemical Engineering Aspects, vol. 191, pp. 3-15, 2001.

[53] J. A. Brant and A. E. Childress, "Membrane-colloid interactions: comparison of extended DLVO predictions with AFM force measurements," Environmental Engineering Science, vol. 19, pp. 413-427, 2002. 